\title{
Community Health Workers' Knowledge, Attitudes and Practices Regarding Malaria Control and Prevention in Bamenda, Cameroon: A Community Based Study
}

Dickson Shey N, Jules Clement AN, Muluh N, Amos Wung B* and Katte Ivo K

Faculty of Health Sciences, University of Buea, Cameroon

\begin{abstract}
Background: Malaria is a major public health problem with about 3.4 billion people at risk worldwide. Community health workers (CHWs) are being used to control and prevent malaria in Cameroonian communities. This study's objectives were to assess CHWs' knowledge, attitudes and practices and the correlates of CHWs' knowledge regarding malaria prevention and control.
\end{abstract}

Methods: A community based cross sectional survey involving $135 \mathrm{CHWs}$ was conducted at the Bamenda Health District from March - May 2015. Data was collected using a structured questionnaire and analysed using Epi Info version 3.5.4.

Result: All the participants had heard of malaria, $97.8 \%$ of them knew malaria was transmitted by mosquitos, $95.5 \%$ of them knew the most common sign/symptom of malaria was high temperature/fever and $98.5 \%$ of the $\mathrm{CHWs}$ knew that sleeping under bed nets protects against mosquito bites. The attitudes of $\mathrm{CHWs}$ regarding malaria prevention and control were somewhat good with $97.0 \%$ of them believing malaria is a life threatening disease and $92.6 \%$ of them believing it is best treated in a hospital. Few CHWs (4.0\%) believed that malaria is caused by witchcraft and $3.3 \%$ of the $\mathrm{CHWs}$ think malaria is best treated by traditional doctors with herbs. CHWs' practices regarding malaria were also good with most $\mathrm{CHWs}$ involved in distribution of nets $(82.7 \%)$. Only being single had a statistically significant association with having knowledge on malaria prevention and control.

Conclusion: Participants knowledge on malaria was high and their attitudes and practices regarding malaria control were also good. Only being single had a statistically significant association to having knowledge on malaria prevention and control. CHWs still need some education and training on malaria prevention/control to provide missing knowledge. Further studies involving larger samples of $\mathrm{CHWs}$ for longer periods of time need to be conducted to find other correlates of CHWs' knowledge on malaria prevention and control.

Key words: Malaria; Community health workers; Knowledge; Attitudes; Practices; Cameroon

Abbreviations: aOR: Adjusted Odds Ratio; ACT: Artemisinine Based Combination Therapy; AIDS: Acquired Immunodeficiency Syndrome; BHD: Bamenda Health District; CHW: Community Health Worker; CI: Confidence Interval; DMO: District Medical Officer; IQR: Interquartile Range; IRB: Institutional Review Board; ITN: Insecticide Treated Net; HIV: Human Immunodeficiency Virus; KAP: Knowledge, Attitudes and Practices; LLINs: Long Lasting Insecticide Nets, MDG: Millennium Development Goal; N: Frequency; NMCP: National Malaria Control Program; OR: Odds Ratio; Ref: Reference Variable; SD: Standard Deviation; TB: Tuberculosis; WHO: World Health Organisation.

\section{Introduction}

Malaria is a major public health problem with 3.4 billion people at risk worldwide [1]. It occurs mostly in poor tropical and sub-tropical areas of the world, causing about $90 \%$ of illnesses and deaths [2]. Globally, malaria is the fifth cause of death from infectious diseases (after respiratory infections, HIV/AIDS, diarrheal diseases, and tuberculosis) and the second leading cause of death from infectious diseases in Africa, after HIV/AIDS [3]. In areas with high transmission, the most vulnerable group of people to malaria are young children and pregnant women $[4,5]$.

In sub Saharan Africa, $80 \%$ of children less than five years old die from malaria [6,7]. In Cameroon, malaria accounts for $30 \%$ of all morbidity cases, $36 \%$ of outpatient consultations, $67 \%$ of childhood deaths and $48 \%$ of all hospital admissions $[8,9]$.
One of the strategies used to fight malaria is the selection and training of community health workers (CHWs) to assist through various practices/activities in the prevention and control of malaria at community level. The CHWs serve as a link between health personnel and community dwellers and carryout activities such as home visits, provision of first aid and treatment of simple and common ailments, provision of health education on maternal and child health, family planning, TB and HIV/AIDS care, malaria control, communicable disease control, and other activities such as collection of data on vital events [3].

It has been documented that utilizing CHWs could help improve health outcomes for large populations in underserved regions $[3,10,11]$. Also, it has been suggested that CHWs are not only cost effective but can enhance the effective implementation of community level health programs especially in the prevention and control of malaria, HIV and

*Corresponding author: Buh Amos Wung, Faculty of Health Sciences, University of Buea, Cameroon, Tel: +237674901233; E-mail: bamosw@yahoo.fr

Received November 27, 2017; Accepted December 04, 2017; Published December 08, 2017

Citation: Dickson Shey N, Jules Clement AN, Muluh N, Amos Wung B, Katte Ivo K (2017) Community Health Workers' Knowledge, Attitudes and Practices Regarding Malaria Control and Prevention in Bamenda, Cameroon: A Community Based Study. J Health Med Informat 8: 294. doi: 10.4172/2157-7420.1000294

Copyright: ( 2017 Dickson Shey N, et al. This is an open-access article distributed under the terms of the Creative Commons Attribution License, which permits unrestricted use, distribution, and reproduction in any medium, provided the original author and source are credited. 
Citation: Dickson Shey N, Jules Clement AN, Muluh N, Amos Wung B, Katte Ivo K (2017) Community Health Workers' Knowledge, Attitudes and Practices Regarding Malaria Control and Prevention in Bamenda, Cameroon: A Community Based Study. J Health Med Informat 8: 294. doi: 10.4172/2157-7420.1000294

Page 2 of 7

Tuberculosis [3,10-13]. Malaria-related activities provided by CHWs include community education on malaria prevention and diagnosis, distribution of insecticide-treated bed nets and provision of homebased management of malaria [11].

However, despite the use of CHWs in Cameroon by the National Malaria Control Program (NMCP) in collaboration with other bodies in the prevention and control of malaria, malaria still stands as the main cause of morbidity and mortality especially among pregnant women and children less than five years old. So, the aim of this study was to assess knowledge, attitudes and practices of CHWs and factors associated to CHWs' knowledge in the prevention and control of malaria.

\section{Methods}

\section{Study design and setting}

A community based cross-sectional descriptive study was conducted among CHWs in the Bamenda Health District (BHD).

Briefly, the BHD is one of the 19 health districts in the North West region. It is located at the heart of the North West Regional Head Quarter (Bamenda) and has a population of about 360,523 inhabitants. It has 17 Health Areas-14 public and 3 confessional. Bamenda has two major seasons-the dry season which is very dry and dusty and the cold rainy season. The town also lies within the forest ecological zone and has many swampy areas which provide favourable breeding grounds for mosquitoes that transmit malaria.

\section{Study population, participants and sampling}

The study involved CHWs of the BHD working in the prevention and control of malaria. To be eligible for the study, a CHW had to be a member of a community of the BHD; resident and working in the BHD. $\mathrm{CHWs}$ who could not give their consent to participate in the study were excluded from the study.

The sample size was calculated using a formula for estimating a single population proportion for a cross-sectional study of an infinite population [14]. We assumed the proportion of CHWs working in malaria prevention and control to be $50 \%$, margin of error of $5 \%$ and a $95 \%$ level of confidence to determine a sample size of 384 . Since the population of CHWs in the BHD was known (200), we did a finite population correction of the sample size and ended up with a sample size of 132 which we rounded up to 135 .

Random sampling was done to select participants. A list of all CHWs of the BHD was obtained at the district head office and random sampling by balloting done to select 135 participants who were invited for the study. If a selected participant refused to give consent to participate in the study, a different participant was selected to replace him. This process continued till the required sample size was reached.

\section{Data collection}

Data was collected by six trained nurses using an English version validated structured questionnaire adopted from two studies $[15,16]$. Prior to collection of data with the questionnaire, it was first pretested in one Community of the BHD. The questionnaire was divided into four sections: Section A on socio-demographic characteristics (sex, age, marital status, religion, education, and employment status); Section B on CHWs' knowledge on malaria prevention and control, Section $\mathrm{C}$ on CHWs' attitudes and Section D on CHWs' practices regarding malaria prevention and control.

\section{Data management and statistical analysis}

The data collected on the printed questionnaire was checked daily for completeness and entered into an electronic questionnaire created in an Epi Info database. The electronic data was saved in a folder in the computer accessible only to the researchers.

Data was analysed using the statistical software programme Epi Info version 3.5.4. Socio-demographic characteristics were described using means, medians, standard deviations and inter-quartile ranges for continuous variables and using frequencies and percentages for categorical variables.

To determine CHWs' knowledge, attitudes and practices regarding malaria prevention and control, questions in the questionnaire were grouped under knowledge, attitudes and practices and the frequencies and percentages of each item was computed.

To assess how socio-demographic characteristics are associated to CHWs knowledge, bivariate and multivariate analyses were done on sex, age, marital status, occupation, religion and educational level. The bivariable analysis was done by considering CHWs' knowledge as binary outcome variable and socio-demographic characteristics as predictors. Unadjusted odd ratios, 95\% confidence intervals and P-values were computed and variables with $\mathrm{P}$-values $\leq 0.25$ [17] were considered as appearing to have an association with knowledge and then added to the multivariate logistic model. The multivariate regression analysis comprised using knowledge as binary outcome variable and sociodemographic characteristics that had p-values $\leq 0.25$ in the bivariate analysis as predictors. Adjusted odds ratios, $95 \%$ confidence intervals and $\mathrm{p}$-values were computed and all variables with $\mathrm{p}$-values $<0.05$ were considered as having a statistically significant association to knowledge on malaria prevention and control.

\section{Ethical considerations}

Ethical approval for the study was obtained from the IRB of the Faculty of Health Sciences (FHS) of the University of Buea (UB) and administrative authorization was obtained from the Dean of FHS, UB and the Regional Delegate of Public Health for the North West Region. All participants provided written informed consent and apart from the inconvenience of taking time to answer the questionnaire, participants were not exposed to any undue risk.

\section{Results}

\section{Demographic characteristics}

Table 1 summarises the socio-demographic characteristic of the 135 participants who took part in this study. The median age of participants was 32 years (IQR: $26-43$ years). Eighty-eight (66.7\%) of the participants were female, $44 \%$ of whom were single. Most participants $(42.7 \%)$ had attended University level of education while $64.4 \%$ of the participants were not employed or doing something that earns them money. With respect to the number of months of work put in as CHWs, the median number of months put in as CHWs was 14 months (IQR: 7-43 months).

\section{CHWs' Knowledge on malaria prevention and control}

Table 2 shows the level of participant's knowledge with regards malaria prevention and control. All participants (100\%) had heard of malaria. One hundred and thirty-two (97.8\%) of participants knew that malaria is transmitted through mosquito bite (Figure 1) and a vast majority of the participants (95.5\%) knew that high temperature/fever is a common sign and symptom of malaria (Figure 2). One hundred and thirty three $(98.5 \%)$ of the participants knew that sleeping under 
Citation: Dickson Shey N, Jules Clement AN, Muluh N, Amos Wung B, Katte Ivo K (2017) Community Health Workers' Knowledge, Attitudes and Practices Regarding Malaria Control and Prevention in Bamenda, Cameroon: A Community Based Study. J Health Med Informat 8: 294. doi: 10.4172/2157-7420.1000294

Page 3 of 7

\begin{tabular}{|c|c|c|}
\hline $\mathrm{CHW}$ characteristic & $\mathrm{N}$ or mean or median & $\%$ or SD or IQR \\
\hline Age & 32 & $26.0-43.0$ \\
\hline \multicolumn{3}{|l|}{ Sex } \\
\hline Male & 44 & 33.3 \\
\hline Female & 88 & 66.7 \\
\hline \multicolumn{3}{|c|}{ Marital status } \\
\hline Single & 59 & 44 \\
\hline Married & 67 & 50 \\
\hline Divorced & 4 & 3 \\
\hline Separated & 1 & 0.7 \\
\hline Widow/widower & 3 & 2.2 \\
\hline \multicolumn{3}{|c|}{ Education } \\
\hline Primary & 17 & 13 \\
\hline Secondary & 33 & 25.2 \\
\hline High school & 25 & 19.1 \\
\hline University & 56 & 42.7 \\
\hline \multicolumn{3}{|c|}{ Employed } \\
\hline yes & 85 & 64.4 \\
\hline No & 47 & 35.6 \\
\hline \multicolumn{3}{|l|}{ Religion } \\
\hline Others & 7 & 5.6 \\
\hline Catholic & 47 & 37.3 \\
\hline Presbyterian & 39 & 31 \\
\hline Baptist & 19 & 15.1 \\
\hline Pentecostal & 14 & 11.1 \\
\hline Duration of work as $\mathrm{CHWs}$ & 14 & $7.00-43.00$ \\
\hline
\end{tabular}

$\mathrm{N}=$ frequency, $\mathrm{SD}=$ standard deviation, \%=percentage, IQR=interquartile range, $\mathrm{CHW}=$ community health worker

Table 1: CHWs' Socio- demographic characteristics.

an insecticide bed net (ITN) was a way to prevent and control malaria while $56.4 \%$ of the participants said that mosquitoes that transmit malaria bite both during the day and night time. More than half $(60.3 \%)$ of participants knew that children less than five years and pregnant women are the most vulnerable group of people affected by malaria. More than half of the participants (57.6\%) claimed they had enough information on malaria prevention and control. Thirty two (49.2\%) of the participants expressed the need for more information on treatment of malaria. Regarding the source from which information on malaria could be communicated, $81.3 \%$ of the participants preferred seminars/ workshops.

\section{CHW' attitudes and practices regarding malaria prevention and control}

The attitudes and practices of CHWs regarding malaria prevention and control are shown in Table 3. Of the 135 participants who took part in the study, $134(97.0 \%)$ agreed that malaria is a serious and life-threatening disease. Majority (88.5\%) of participants agreed that malaria can be prevented by avoiding mosquito bites and $92.6 \%$ of the participants agreed that malaria is best treated in the hospital. However, a small proportion of the participants (12.6\%) wrongly agreed that malaria can be transmitted like common cold. Five $(4.0 \%)$ of the participants said that malaria is caused by witchcraft and $3.3 \%$ of the participants felt that malaria is best treated by traditional doctors with the use of herbs.

Regarding CHWs' practices, $82.7 \%$ of them were involved in the distribution of ITNs in the community. Majority $(97.7 \%)$ of the CHWs were involved in giving health education on hygiene and sanitation in the community as a means to prevent and control malaria. One

\begin{tabular}{|c|c|c|}
\hline $\begin{array}{l}\text { CHW's adequate Knowledge in malaria prevention and } \\
\text { control }\end{array}$ & $\mathbf{N}$ & $\%$ \\
\hline Heard about malaria & 135 & 100 \\
\hline \multicolumn{3}{|l|}{ Ways to prevent/control malaria: } \\
\hline Sleeping under bed net & 133 & 98.5 \\
\hline Wear long sleeve clothes & 61 & 42.2 \\
\hline Making fire and smoke & 3 & 2.2 \\
\hline Spraying insecticides & 93 & 68.9 \\
\hline Clear bushes around the house & 95 & 70.4 \\
\hline Cleaning house & 78 & 57.8 \\
\hline \multicolumn{3}{|l|}{ Mosquitoes bite during: } \\
\hline Day time & 4 & 3 \\
\hline Night time & 61 & 45.9 \\
\hline Both day and Night & 75 & 56.4 \\
\hline \multicolumn{3}{|l|}{ Groups most affected by malaria: } \\
\hline Adults & 21 & 16 \\
\hline Children < 5years & 53 & 40.5 \\
\hline Pregnant women & 43 & 32.8 \\
\hline Children $<5$ and pregnant women & 79 & 60.3 \\
\hline Think have enough information on malaria & 76 & 57.6 \\
\hline \multicolumn{3}{|l|}{ Preferred information to get on malaria: } \\
\hline Information on treatment & 32 & 49.2 \\
\hline Information on control & 29 & 44.6 \\
\hline Information on prevention & 31 & 47.7 \\
\hline Information on signs and symptoms & 23 & 35.4 \\
\hline Nature of the disease & 29 & 44.6 \\
\hline Any information & 17 & 26.2 \\
\hline \multicolumn{3}{|l|}{ Source of information } \\
\hline Seminars/workshop & 78 & 81.3 \\
\hline Health center/clinics & 55 & 57.3 \\
\hline Formal training in schools & 32 & 33.3 \\
\hline
\end{tabular}

Table 2: CHWs' Knowledge in malaria prevention and control in the Bamenda health district.

hundred and eleven CHWs (94.9\%) said that they themselves and community members use bed nets as a means to prevent and control mosquito bites. Most participants (88.1\%) were trained on ways to prevent and control malaria, $70.7 \%$ of them were actually involved in demonstrating how nets can be mounted in the community and $40.6 \%$ of them were involved in carrying out indoor spraying of houses with insecticides to prevent and control malaria. However, the proportion of CHWs distributing information leaflets on malaria prevention and control, carrying out home diagnosis and treatment of malaria with Artemisinine based combination therapy (ACT), giving intermittent preventive treatment of malaria to pregnant women and referring severe cases of malaria in children to hospital were $45.1 \%, 47.4 \%, 32.8 \%$ and $63.9 \%$ respectively.

\section{Correlates of CHWs' knowledge in the prevention and control of malaria}

The socio-demographic correlates of CHWs' knowledge on malaria prevention and control are presented on Tables 4 and 5. Five variables appeared to have an association with knowledge in the bivariate analysis (having increasing age, being female, being married/divorced/ separated, and being a Catholic/Presbyterian/Baptist Christian and having worked for more months as a CHW). In fact, the odds of having knowledge on malaria prevention and control in participants aged 4150 years was 0.40 times $(95 \%$ CI: $0.15,1.50)$ that in participants who were aged 21-30 years while the odds of having knowledge on malaria 
Citation: Dickson Shey N, Jules Clement AN, Muluh N, Amos Wung B, Katte Ivo K (2017) Community Health Workers' Knowledge, Attitudes and Practices Regarding Malaria Control and Prevention in Bamenda, Cameroon: A Community Based Study. J Health Med Informat 8: 294. doi: 10.4172/2157-7420.1000294

Page 4 of 7

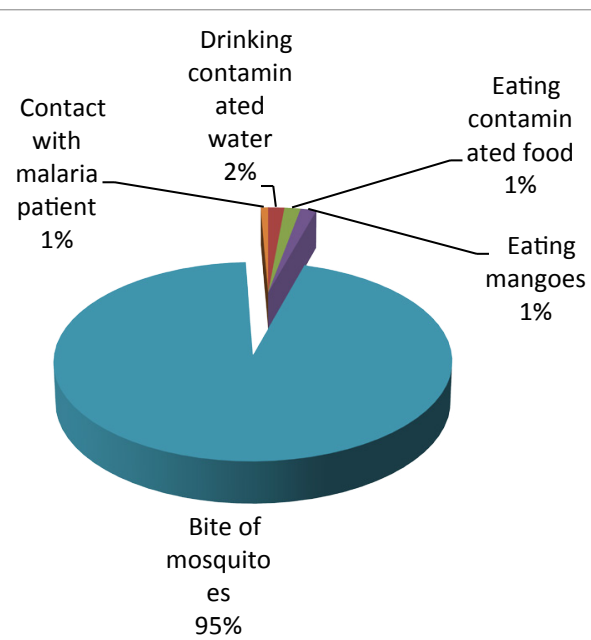

Figure 1: Participants' knowledge on modes of transmission of malaria.

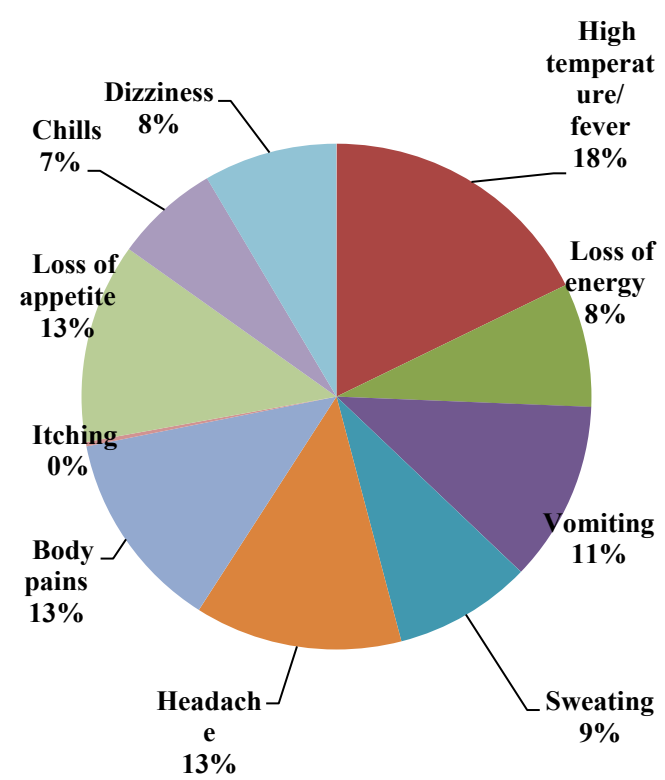

Figure 2: Participants' knowledge on common signs/symptoms of malaria.

prevention and control in CHWs aged 51 and above was 0.36 times (95\% CI: $0.10,1.30)$ that in participants who were aged $21-30$ years. The odds of having knowledge on malaria prevention and control in participants who were female was 1.67 times $(95 \%$ CI: $0.79,3.56)$ that in participants who were males. Also, the odds of having knowledge on the prevention and control of malaria comparing participants who were married to participants who were single was 0.36 times $(95 \%$ CI: $0.17,0.74)$ while the odds of having knowledge on the prevention and control of malaria in participants who were divorced, separated or widowed was 0.09 times (95\% CI: $0.01,0.79)$ that in participants who were single. The odds of having knowledge on the prevention and control of malaria in participants who were Catholic, Presbyterian or Baptist Christians was 1.96 times (95\% CI: 0.73, 5.25) that in participants who were Pentecostal/other religions. Finally, the odds of having knowledge on the prevention and control of malaria in participants who had worked for 25 or more months was 0.61 times (95\%CI: $0.28,1.35)$ that in participants who had worked for only 12 months or less as a community health worker (Table 4 ).

\begin{tabular}{|l|c|c|}
\hline CHWs attitudes on malaria prevention and control & N & $\%$ \\
\hline Malaria is a serious and life threatening diseases & 134 & 97 \\
\hline Malaria can be transmitted like common cold & 16 & 12.6 \\
\hline Malaria can be prevented by avoiding mosquito bite & 116 & 88.5 \\
\hline Malaria is caused by witchcraft & 5 & 4 \\
\hline Malaria is best treated in the hospital & 125 & 92.6 \\
\hline Malaria is best treated by traditional doctors or with herbs & 4 & 3.3 \\
\hline CHWs practices regarding malaria prevention and control & & \\
\hline Use impregnated bed net in community & 119 & 88.1 \\
\hline Distribute bed nets to community & 110 & 82.7 \\
\hline $\begin{array}{l}\text { Give health education on hygiene and sanitation in the } \\
\text { community }\end{array}$ & 130 & 97.7 \\
\hline Involved in home diagnosis and treatment with ACT & 63 & 47.4 \\
\hline Give intermittent prevention treatment to pregnant women & 43 & 32.8 \\
\hline Involved in indoor spraying to kill mosquitos & 54 & 40.6 \\
\hline Distribute information leaflets on malaria & 60 & 45.1 \\
\hline Have receive training on malaria & 111 & 94.9 \\
\hline Source of training: & 66 & 57.4 \\
\hline Seminars/workshops & 31 & 27 \\
\hline Training in schools & 14 & 12.2 \\
\hline Radio/television & 83.9 \\
\hline Newspapers/posters/pamphlets & 7 \\
\hline Churches & & \\
\hline
\end{tabular}

$\mathrm{CHWs}=$ community health workers, $\mathrm{N}=$ frequency of $\mathrm{CHWs}$ agreeing or strongly agreeing, \%=percentage of $\mathrm{CHWs}$ agreeing or strongly agreeing,

Table 3: CHWs' attitudes and practices regarding malaria prevention and control in the Bamenda health district.

After controlling for potential confounding by each of the sociodemographic factors that appeared to have an association with knowledge in the bivariate analysis, only one variable had a statistically significant association with CHWs' knowledge on malaria prevention and control in the BHD (being single). The odds of having knowledge in the prevention and control of malaria in participants who were married was 0.28 times (95\% CI: $0.10,0.80)$ that in participants who were single (Table 5).

\section{Discussion}

Malaria is a serious public health problem causing between 1.5 to 2.7 million deaths and 300 to 500 million clinical cases in tropical and sub-tropical areas each year [18]. An important prerequisite for successful malaria control interventions is assessing and analysing local malaria problems [19].

In this study, to appreciate CHWs' knowledge, attitudes and practices (KAP) regarding malaria prevention and the correlates of CHWs' knowledge in the prevention of malaria, we assessed the proportion of CHWs who had knowledge on some aspects of malaria prevention, CHWs' attitudes on malaria prevention, CHWs' practices regarding malaria prevention and the association between $\mathrm{CHWs}$ socio-demographic characteristics and their knowledge on malaria prevention and control. We document that all the participants had once heard of malaria, that the proportion of participants who know 
Citation: Dickson Shey N, Jules Clement AN, Muluh N, Amos Wung B, Katte Ivo K (2017) Community Health Workers' Knowledge, Attitudes and Practices Regarding Malaria Control and Prevention in Bamenda, Cameroon: A Community Based Study. J Health Med Informat 8: 294. doi: 10.4172/2157-7420.1000294

Page 5 of 7

\begin{tabular}{|c|c|c|c|c|c|}
\hline Socio-Demographic characteristics & $\mathbf{N}$ & $\%$ & $\begin{array}{l}\text { Knowledge on Malaria prevention and } \\
\text { control }\end{array}$ & & P-value \\
\hline & & & $\mathrm{OR}^{*}$ & $95 \% \mathrm{Cl}$ & \\
\hline \multicolumn{6}{|l|}{ Age } \\
\hline $21-30$ & 31 & 55.4 & Ref & & \\
\hline $31-40$ & 17 & 44.7 & 0.65 & $0.29-1.50$ & 0.31 \\
\hline $41-50$ & 9 & 33.3 & 0.4 & $0.15-1.05$ & 0.06 \\
\hline $51+$ & 4 & 30.8 & 0.36 & $0.10-1.30$ & 0.12 \\
\hline \multicolumn{6}{|l|}{ Sex } \\
\hline Female & 43 & 48.9 & 1.67 & 0.79 & 0.17 \\
\hline Male & 16 & 36.4 & Ref & & \\
\hline \multicolumn{6}{|l|}{ Marital status } \\
\hline Single & 36 & 61 & Ref & & \\
\hline Married & 24 & 35.8 & 0.36 & $0.17-0.74$ & 0.01 \\
\hline Divorced/separated/widow/widower & 1 & 12.5 & 0.09 & $0.01-0.79$ & 0.03 \\
\hline \multicolumn{6}{|l|}{ Education $^{\star *}$} \\
\hline Primary & 8 & 47.1 & Ref & & \\
\hline Secondary & 14 & 42.4 & 0.83 & $0.26-2.69$ & 0.75 \\
\hline High school/University & 39 & 48.1 & 1.04 & $0.37-2.98$ & 0.93 \\
\hline \multicolumn{6}{|l|}{ Religion } \\
\hline Others/Pentecostal & 7 & 33.3 & Ref & & \\
\hline Catholics/Presbyterian/Baptist. & 52 & 49.5 & 1.96 & $0.73-5.25$ & 0.17 \\
\hline \multicolumn{6}{|l|}{ Employed } \\
\hline Yes & 43 & 50.6 & 0.66 & $0.32-1.36$ & 0.26 \\
\hline No & 19 & 40.4 & Ref & & \\
\hline \multicolumn{6}{|c|}{ Months of work as $\mathrm{CHW}$} \\
\hline$\leq 12$ & 31 & 49.2 & Ref & & \\
\hline $13-24$ & 11 & 50 & 1.03 & $0.39-2.73$ & 0.95 \\
\hline $25+$ Months & 16 & 37.2 & 0.61 & $0.28-1.35$ & 0.22 \\
\hline
\end{tabular}

${ }^{*} \mathrm{OR}=$ unadjusted odds ratio, ${ }^{*}$ Primary education at most seven years, OR=odds ratio, Ref= reference variable category, $\mathrm{Cl}=$ confidence interval, $\mathrm{P}$-values $<0.25$ suggests possible association to knowledge.

Table 4: Correlates of CHWs' knowledge in the prevention and control of malaria in the BHD.

that malaria is transmitted by mosquitoes, that the most common sign and symptom of malaria is high temperature/fever and that sleeping under bed nets protects against mosquito bites is high. Despite this, we document that the proportion of CHWs who know the right time that mosquitoes bite, know the group of persons most affected by malaria and who said they had adequate knowledge on malaria prevention and control are somehow low (45.9\%, 60.3\% and 57.6\% respectively).

Also, we document that the attitudes of CHWs regarding malaria prevention and control are somewhat good with $97.0 \%, 88.5 \%$ and $92.6 \%$ believing respectively that malaria is a life threatening disease, that it can be prevented by avoiding mosquito bites and that it can be best treated in hospital. Nonetheless, a small proportion of CHWs $4.0 \%$ and $3.3 \%$ respectively believe that malaria is caused by witchcraft and that it can only be best treated by traditional doctors with herbs.

The practices of CHWs with regards malaria prevention and control are also good with a high proportion of the CHWs involved in distribution of nets, giving of health education on hygiene and sanitation in the communities, referring severe cases of malaria in children to hospital and sleeping under treated bed nets.

However, available CHWs' socio-demographic characteristics did not significantly show any association to their knowledge on malaria prevention and control. Actually, only one variable (being single) had a statistically significant association with having knowledge on malaria prevention and control. While the level of CHWs' knowledge and attitudes on malaria prevention and control seems high in this study, it falls within the range of good knowledge and attitudes (5099\%) recorded in similar studies conducted in Colombia [20], India [21], Ethiopia [22], Iran [23], Tanzania [24], Ghana [25], Nigeria [26] and Cameroon [27]. The highest level of knowledge (99\%) on malaria transmission, prevention and control so far has been reported in a study done in Cameroon [27].

We also report high levels of good practices of participants in this study with regards malaria prevention and control which however is different from the traditional medicine practices and other gaps in practices identified in studies done in Colombia [20] and India [21]. Our study showed a statistical significant association with knowledge on malaria prevention and only one socio-demographic characteristic (being single). This result is similar to that of a study in Iran that did not find any significant association between knowledge on malaria control and socio-demographic factors [23] but dissimilar to studies that at least found an association with knowledge on malaria prevention and level of education in Nigeria [26], Ghana [25], Tanzania [24] and Cameroon [27]. We did not investigate the association between CHWs' attitudes and practices with their socio-demographic characteristics. Nonetheless, we think that participants knowledge on malaria prevention and control influences their attitudes and practices and as such factors associated to knowledge should possibly be associated to CHWs' attitudes and practices. 
Citation: Dickson Shey N, Jules Clement AN, Muluh N, Amos Wung B, Katte Ivo K (2017) Community Health Workers' Knowledge, Attitudes and Practices Regarding Malaria Control and Prevention in Bamenda, Cameroon: A Community Based Study. J Health Med Informat 8: 294. doi: 10.4172/2157-7420.1000294

Page 6 of 7

\begin{tabular}{|c|c|c|c|c|c|}
\hline $\begin{array}{c}\text { Socio- } \\
\text { Demographic } \\
\text { characteristics }\end{array}$ & $\mathbf{N}$ & $\%$ & $\begin{array}{c}\text { Knowledge } \\
\text { on Malaria } \\
\text { prevention and } \\
\text { control }\end{array}$ & & P-value \\
\hline & & & $\mathrm{aOR}^{*}$ & $95 \% \mathrm{Cl}$ & \\
\hline \multicolumn{6}{|l|}{ Age } \\
\hline $21-30$ & 31 & 55.4 & Ref & & \\
\hline $31-40$ & 17 & 44.7 & 1.22 & $0.39-3.79$ & 0.73 \\
\hline $41-50$ & 9 & 33.3 & 1.19 & $0.32-4.47$ & 0.8 \\
\hline $51+$ years & 4 & 30.8 & 0.72 & $0.13-4.16$ & 0.72 \\
\hline \multicolumn{6}{|l|}{ Sex } \\
\hline Female & 43 & 48.9 & 1.83 & $0.77-4.37$ & 0.17 \\
\hline Male & 16 & 36.4 & Ref & & \\
\hline \multicolumn{6}{|c|}{ Marital status } \\
\hline Single & 36 & 61 & Ref & & \\
\hline Married & 24 & 35.8 & 0.28 & $0.10-0.80$ & 0.02 \\
\hline $\begin{array}{l}\text { Divorced/ } \\
\text { Separated/ }\end{array}$ & 1 & 12-May & 0.08 & $0.01-0.88$ & 0.04 \\
\hline \multicolumn{6}{|c|}{ Widow/Widower } \\
\hline \multicolumn{6}{|l|}{ Religion } \\
\hline \multirow[t]{2}{*}{$\begin{array}{l}\text { Others/ } \\
\text { Pentecostal } \\
\text { Catholics/ } \\
\text { Presbyterian/ } \\
\text { Baptist. }\end{array}$} & 7 & 33.3 & Ref & & \\
\hline & 52 & 49.5 & 1.63 & $0.49-5.41$ & 0.43 \\
\hline \multicolumn{6}{|c|}{ Months of work as $\mathrm{CHW}$} \\
\hline$\leq 12$ & 31 & 49.2 & Ref & & \\
\hline $13-24$ & 11 & 50 & 1.83 & $0.55-6.08$ & 0.33 \\
\hline $25+$ Months & 16 & 37.2 & 0.95 & $0.35-2.59$ & 0.91 \\
\hline
\end{tabular}

*aOR=adjusted odds ratio, OR=odds ratio, Ref= reference variable category, $\mathrm{Cl}=$ confidence interval, $\mathrm{P}$-values $<0.05$ are statistically significant.

Table 5: Correlates of CHWs' knowledge in the prevention and control of malaria in the BHD (Multivariate analysis).

We did not find previous studies done on CHWs' knowledge, attitudes and practices regarding malaria prevention both locally and globally. Most studies we found were done on community members KAP on malaria prevention and control in Italy [18], Iran [16], Ethiopia $[22,28]$ and Nigeria [23].

The results of our study may be limited by the fact that our sample size was small and that we did not use all the community health workers in the BHD. However, we used well trained personnel to collect data and our sample size was representative of the $\mathrm{CHWs}$ ' population in the BHD. So, even if we had a larger sample, we believe the results will not differ significantly.

Considering that some CHWs are not informed on when mosquitoes bite and group of people most affected by malaria, considering that some CHWs feel that malaria can be transmitted like common cold, that it is caused by witchcraft and that it can only be best treated by traditional doctors with use of herbs, and considering that some of the CHWs' practices such as distribution of information leaflets, indoor spraying to kill mosquitoes, providing intermittent preventive treatment to pregnant women and carrying out home diagnosis of malaria recorded somehow low proportions, we think this shows a lack of knowledge and reiterates a need for some training and education of CHWs on malaria prevention and control to provide missing knowledge, so that they could better serve their communities.

\section{Conclusion}

The knowledge of community health workers regarding malaria, its causes and common signs and symptoms is high. Their attitudes regarding prevention of malaria by avoiding mosquitoes bite and treating malaria in hospital are good and their practices with respect to malaria prevention and control is also somehow good. Only being single had a statistically significant association to having knowledge on malaria prevention and control. CHWs need some education and training on malaria prevention/control to provide missing knowledge and further studies involving larger samples of CHWs for longer periods of time need to be done to find other correlates of CHWs' knowledge on malaria prevention and control.

\section{Ethics Approval and Consent to Participate}

Ethical approval for this study was obtained from the IRB of the Faculty of Health Sciences of the University of Buea. Written consent was obtained from all participants prior to participation in the study.

\section{Consent for Publication}

Not applicable.

\section{Availability of Data and Materials}

The authors declare that data and materials shall be available only on request.

\section{Competing Interests}

The authors declare that they have no competing interests.

\section{Authors' Contributions}

NDS, NM, BAW, KKI and ANJC conceived the research questions, NM designed the study protocol and collected data; NM and BAW analyzed data. BAW assisted with data interpretation; NM, BAW, NDS, KKI and ANJC all assisted with study design. All authors wrote and or reviewed the manuscript.

\section{Acknowledgements}

We thank all study participants and our data collectors. We also thank the Institutional Review Board of the Faculty of Health Sciences of the University of Buea which gave ethical clearance for this study, the Dean of the Faculty of Health Sciences of the University of Buea (Pr. Ngowe Ngowe Marcelin) and the Regional Delegate of Public Health for the North West Region (Dr Ndiforchu Afanui Victor) who gave administrative authorizations for this study to be conducted.

\section{Funding}

Study was not funded.

\section{References}

1. http://www.who.int/malaria/publications/world_malaria_report_2013/en/

2. Menéndez C, D’Alessandro U, Ter Kuile FO (2007) Reducing the burden of malaria in pregnancy by preventive strategies. Lancet Infect Dis 7: 126-135.

3. http://www.hrhresourcecenter.org/node/1587

4. Rajahram GS, Barber BE, William T, Menon J, Anstey NM, et al. (2012) Deaths due to Plasmodium knowlesi malaria in Sabah, Malaysia: association with reporting as Plasmodium malariae and delayed parenteral artesunate. Malar J 11: 284.

5. Delacollette C, Van der Stuyft P, Molima K (1996) Using community health workers for malaria control: experience in Zaire. Bull World Health Organ 74 423-430.

6. Eisele TP, Larsen DA, Walker N, Cibulskis RE, Yukich JO, et al. (2012) Estimates of child deaths prevented from malaria prevention scale-up in Africa 2001-2010. Malar J 11: 93. 
Citation: Dickson Shey N, Jules Clement AN, Muluh N, Amos Wung B, Katte Ivo K (2017) Community Health Workers' Knowledge, Attitudes and Practices Regarding Malaria Control and Prevention in Bamenda, Cameroon: A Community Based Study. J Health Med Informat 8: 294. doi: 10.4172/2157-7420.1000294

7. Sayang C, Gausseres M, Vernazza-Licht N, Malvy D, Bley D, et al. (2009) Treatment of malaria from monotherapy to artemisinin-based combination therapy by health professionals in urban health facilities in Yaoundé, central province, Cameroon. Malar J 8: 176.

8. http://www.who.int/malaria/world_malaria_report_2011/en/

9. Zofou D, Nyasa RB, Nsagha DS, Ntie-Kang F, Meriki HD, et al. (2014) Control of malaria and other vector-borne protozoan diseases in the tropics: enduring challenges despite considerable progress and achievements. Infect Dis Poverty 3: 1

10. Young M, Wolfheim C, Marsh DR, Hammamy D (2012) World Health Organization/United Nations Children's Fund Joint Statement on Integrated Community Case Management: An Equity-Focused Strategy to Improve Access to Essential Treatment Services for Children. Am J Trop Med Hyg 87: 6-10.

11. http://www.hrhresourcecenter.org/node/3976

12. http://www.who.int/maternal_child_adolescent/documents/9789280639858/en/

13. http://www.who.int/malaria/publications/world_malaria_report_2014/report/en/

14. https://www.researchgate.net/publication/45459002_Pratical_Issues_in_ Calculating_the_Sample_Size_for_Prevalence_Studies

15. Mwanje LF (2013) Knowledge, attitudes and practices on malaria prevention and control in Uganda. MUSPHC 2013: 1-123.

16. Fekri S, Vatandoost H, Daryanavard A, Shahi M, Safari R, et al. (2014) Malaria situation in an endemic area, southeastern iran. J Arthropod-Borne Dis 8: 82-90.

17. Bursac Z, Gauss CH, Williams DK, Hosmer DW (2008) Purposeful selection of variables in logistic regression. Source Code Biol Med 3: 17.

18. Scolari C, Tedoldi S, Casalini C, Scarcella C, Matteelli A, et al. (2002) Knowledge, attitudes, and practices on malaria preventive measures of migrants attending a public health clinic in northern Italy. J Travel Med 9: 160-162.
19. Erhun WO, Agbani EO, Adesanya SO (2006) Malaria prevention: knowledge, attitude and practice in a Southwestern Nigerian community. Afr J Biomed Res 8: 25-29.

20. Forero DA, Chaparro PE, Vallejo AF, Benavides Y, Gutiérrez JB, et al. (2014) Knowledge, attitudes and practices of malaria in Colombia. Malar J 13: 165.

21. Sabin LL, Rizal A, Brooks MI, Singh MP, Tuchman J, et al. (2010) Attitudes knowledge, and practices regarding malaria prevention and treatment among pregnant women in Eastern India. Am J Trop Med Hyg 82: 1010-1016.

22. http://www.readcube.com/articles/10.4172\%2F2329-891X.1000118

23. Hanafi-Bojd AA, Vatandoost $H$, Oshaghi MA, Eshraghian MR, Haghdoost AA et al. (2011) Knowledge, attitudes and practices regarding malaria control in an endemic area of southern Iran. Southeast Asian J Trop Med Public Health 42: 491-501.

24. Mazigo HD, Obasy E, Mauka W, Manyiri P, Zinga M, et al. (2010) Knowledge Attitudes, and Practices about Malaria and Its Control in Rural Northwest Tanzania, Knowledge, Attitudes, and Practices about Malaria and Its Control in Rural Northwest Tanzania. Malar Res Treat Malar Res Treat 2010: e794261.

25. Darkwah IA, Nyarko SKB (2011) Knowledge of Malaria Prevention and Control in a Sub-Urban Community in Accra, Ghana. Int J Trop Med 6: 61-69.

26. Adedotun AA, Morenikeji OA, Odaibo AB (2010) Knowledge, attitudes and practices about malaria in an urban community in south-western Nigeria. $J$ Vector Borne Dis 47: 155-159.

27. Kimbi HK, Nkesa SB, Ndamukong-Nyanga JL, Sumbele IUN, Atashili J, et al. (2014) Knowledge and perceptions towards malaria prevention among vulnerable groups in the Buea Health District, Cameroon. BMC Public Health 14: 883 .

28. Abate A, Degarege A, Erko B (2013) Community knowledge, attitude and practice about malaria in a low endemic setting of Shewa Robit Town northeastern Ethiopia. BMC Public Health 13: 312 